\title{
Calving on tidewater glaciers amplified by submarine frontal melting
}

\author{
M. O'Leary ${ }^{1,2}$ and P. Christoffersen ${ }^{1}$ \\ ${ }^{1}$ Scott Polar Research Institute, University of Cambridge, Cambridge, UK \\ ${ }^{2}$ Department of Atmospheric, Oceanic and Space Sciences, University of Michigan, Ann Arbor, MI, USA
}

Correspondence to: M. O’Leary (olearym@umich.edu)

Received: 17 June 2012 - Published in The Cryosphere Discuss.: 8 August 2012

Revised: 1 November 2012 - Accepted: 28 November 2012 - Published: 28 January 2013

\begin{abstract}
While it has been shown repeatedly that ocean conditions exhibit an important control on the behaviour of grounded tidewater glaciers, modelling studies have focused largely on the effects of basal and surface melting. Here, a finite-element model of stresses near the front of a tidewater glacier is used to investigate the effects of frontal melting on calving, independently of the calving criterion used. Applications of the stress model to idealized scenarios reveal that undercutting of the ice front due to frontal melting can drive calving at up to ten times the mean melt rate. Factors which cause increased frontal melt-driven calving include a strong thermal gradient in the ice, and a concentration of frontal melt at the base of the glacier. These properties are typical of both Arctic and Antarctic tidewater glaciers. The finding that frontal melt near the base is a strong driver of calving leads to the conclusion that water temperatures near the bed of the glacier are critically important to the glacier front, and thus the flow of the glacier. These conclusions are robust against changes in the basal boundary condition and the choice of calving criterion, as well as variations in the glacier size or level of crevassing.
\end{abstract}

\section{Introduction}

While it is widely acknowledged that iceberg calving is an important factor in both the mass balance of major ice sheets (Rignot and Kanagaratnam, 2006) and the dynamics of tidewater glaciers (Joughin et al., 2004; Luckman et al., 2006; Stearns and Hamilton, 2007; Howat et al., 2007), the modelling of calving processes is still problematic. This has led to a great deal of uncertainty in predictions of the future behaviour of these glaciers, and their consequent contributions to sea-level rise.

Reviewing the mechanisms of calving at tidewater glaciers, Benn et al. (2007b) distinguish between calving mechanisms associated with longitudinal stretching of the glacier, and those mechanisms associated with buoyant forcing at the front. A calving law based on simplified physics (Benn et al., 2007a) has shown some success in replicating the first of these kinds of processes (Mottram and Benn, 2009; Nick et al., 2010; Cook et al., 2012). However, no model exists in current practice to account for the buoyant processes, despite the possibility that these may account for the majority of calving in some circumstances.

It was first noted by Weertman (1957a) that there is a necessary imbalance at any ice front between the glaciostatic pressure outwards and the hydrostatic pressure inwards. In floating ice this imbalance manifests itself as a pure bending moment acting on the ice front, while in grounded ice it partially expresses itself as a net outward force. Reeh (1968) demonstrated the consequences of this effect on an analytic model of an ice shelf with a Newtonian rheology. He showed that a maximum in both tensile stress and surface elevation develops about one ice thickness from the front, and that this stress leads to calving, with the calving rate determined by the glacier's thickness and viscosity. He also noted the possible effects of variations in the shape of the ice front, although these were not incorporated into his model.

The idea that frontal melting could be a driver of calving has been mentioned by a number of authors (Hanson and Hooke, 2000; Vieli et al., 2002), but there have been few quantitative studies of the phenomenon. A number of authors (Kirkbride and Warren, 1997; Benn et al., 2001; Röhl, 
2006) have identified the melting and erosion of waterline notches in lake-terminating glaciers as controls on their calving rates. Similarly, estimates of frontal melting at LeConte Glacier, Alaska, (Motyka et al., 2003) and several Greenlandic glaciers (Rignot et al., 2010; Sutherland and Straneo, 2012) show that melting may be an important term in the frontal mass balance of these glaciers. Jenkins (2011) has provided some explanation of these results, using a model of plume-driven melting. Given the evidence for the importance of frontal melt as a mass balance term, and the likelihood of a connection with calving processes, it has become a subject of interest how tidewater glaciers react to melt-driven changes in their front geometry.

The difficulty in understanding interactions between frontal melting and calving stems from the fact that the detailed physics of the fracture process which leads to calving are unknown, and likely far too complex to be usefully modelled. As such, in this paper we take an approach which is based on the changes in the stress field which are induced by undercutting of an ice front. Assuming that fracture is a function of stress, and without prejudice as to the form of this function, we can compare the stress regimes of idealized glaciers with and without undercutting, and thus infer changes in calving behaviour.

As a preliminary, in Sect. 2 we outline the model equations, boundary conditions and implementation which we use to calculate the stress fields within the glacier. In Sect. 3, we describe a key concept to this study, that of "stress retreat". This quantifies the displacement of the stress field due to a perturbation, in this case frontal undercutting. We posit that this displacement also corresponds to a change in the point of fracture, based on the assumption that fracture is purely determined by the stress field. We can then define a "calving multiplier", the ratio of the stress retreat to the length of the undercut, which provides a measure of the extra calving induced by frontal melting.

Section 4 demonstrates our first key result, namely that the stress retreat is a linear multiple of the undercut length, or, equivalently, that the calving multiplier is independent of the undercut length. We follow this up in Sect. 5 with an examination of how the calving multiplier varies, depending on the geometry of the glacier, and other environmental factors. Specifically, we show that frontal melting has the largest effect on calving when (1) the glacier is near flotation, (2) there is a strong thermal gradient in the ice, and (3) when melt is focused near the base of the glacier.

\section{Ice flow model}

\subsection{Flow of ice}

While ice exhibits visco-elastic properties on hourly to daily timescales, the motion of glaciers over timescales longer than about a day is best described as that of viscous fluid flow
(Paterson, 2000). As the Reynolds numbers involved are extremely low, of the order of $10^{-13}$, and the ice density is constant throughout most of the glacier body, the flow can be approximated using the incompressible Stokes equations:

$$
\begin{aligned}
\nabla p & =\mu \nabla^{2} u+f, \\
\nabla \cdot u & =0 .
\end{aligned}
$$

Here, $p$ is the scalar pressure, $u$ is the flow velocity, $f$ is the body force (in this case gravity), and $\mu$ is the dynamic viscosity of the fluid. As ice exhibits non-Newtonian flow properties, $\mu$ is itself a function of the velocity field, and must be specified through a flow law.

The most common flow law in use for glaciological purposes is that derived by Glen (1952). This is most simply expressed as a relationship between the stress and strain tensors. The deviatoric stress tensor is denoted here by $\tau_{i j}$, and the second invariant of this tensor calculated as:

$2 \tau^{2}=\sum_{i, j} \tau_{i j}^{2}$

The strain rates $\dot{\epsilon}_{i j}=\frac{1}{2}\left(\frac{\partial u_{i}}{\partial x_{j}}+\frac{\partial u_{j}}{\partial x_{i}}\right)$ can then be expressed as a function of the deviatoric stresses:

$\dot{\epsilon}_{i j}=A \tau^{n-1} \tau_{i j}$.

The quantities $A$ and $n$ are considered parameters of the flow law. In this work, $n$ is fixed at its conventional value of 3 , and $A$ is allowed to vary as a function of temperature $T$ :

$A=A_{0} \exp (-Q / R T)$.

The universal gas constant $R$ is fixed, while the activation energy $Q$ and the multiplicative factor $A_{0}$ are chosen to match measurements. For the purposes of this study, standard values are used for $Q$ and $A_{0}$, as given by Paterson (2000).

To translate between the stress-strain relationship of Eq. (4) and the viscosity-based Stokes formulation, Glen's law is inverted, giving the effective viscosity in terms of the strain rates and the flow parameter $A$ :

$\mu=A^{-1 / n}\left(\sum_{i, j} \dot{\epsilon}_{i j}^{2}\right)^{\frac{1-n}{2 n}}$.

\subsection{Boundary conditions}

On the upper surface of the glacier, as well as that portion of the front which is above the waterline, a stress-free boundary condition is applied. Below the waterline, hydrostatic pressure is applied. At the rear of the domain, far from the front, the flow velocity is set to a constant of $1 \mathrm{~km} \mathrm{a}^{-1}$. Sensitivity tests (not shown here) indicate that the results are largely insensitive to this value.

The basal boundary condition for glacier flow is an active topic of research, and several relationships have been proposed. The most common of these are those based on the 
work of Weertman (1957b), who gives a power law relationship between basal shear stress $\tau_{\mathrm{b}}$, basal velocity $u_{\mathrm{b}}$, and the effective pressure at the base $N=p_{\mathrm{i}}-p_{\mathrm{w}}$ :

$\tau_{\mathrm{b}}=k u_{\mathrm{b}}^{p} N^{-q}$.

This relationship, while convenient numerically, and difficult to disprove empirically, has been shown to have difficulties, notably the lack of an upper bound for shear stress. A calculation by Iken (1981) showed that for a bounded basal slope, such a bound must exist. This result was reproduced in a more general setting by Schoof (2005), who suggested a relationship which was refined by Gagliardini et al. (2007):

$\tau_{\mathrm{b}}=C N\left(1+\frac{\lambda^{*} A C^{n} N^{n}}{m^{*} u}\right)^{-1 / n}$.

Here, $\lambda^{*}$ and $m^{*}$ are the dominant wavelength and slope of bed features, and $C$ is a constant subject to the inequality $C \leq m^{*}$. Following Pimentel et al. (2010), the relationship $C=0.84 m^{*}$ is used, based on the result for a sinusoidal bed. We assume that water pressure is hydrostatic, based on a free connection to the ocean.

\subsection{Numerics}

For the purposes of this study, a 2-D solution to the incompressible Stokes equations is sought, using Glen's flow law as a constitutive relation. The glacier is treated as of uniform width, and sufficiently wide that lateral boundary effects are unimportant.

Such a solution is produced using the free open-source finite element solver FreeFem++ (Hecht et al., 2005), using a standard triangular $\mathrm{P} 2$ element for the velocity field and a P1 element for the pressure, both implemented on an unstructured grid. A finite element implementation allows the model to easily handle a variety of geometries, as well as allowing the model's resolution to be focused on the areas of interest. In order to handle the implicit definition of $\mu$ through Eq. (6), the system is solved iteratively, beginning with the Newtonian solution.

The basal boundary condition (Eq. 8) is also non-linear, which presents some difficulties in the numerical implementation. A Robin-type boundary condition is used, expressing $\tau_{\mathrm{b}}$ as a linear multiple of $u$ at the base, and recalculating the constant of proportionality with each step of the non-linear iteration procedure. This iterative process is combined with that for the effective viscosity, in order to reduce the total number of iterations required.

This procedure is found to be much more numerically stable than the alternatives, such as Dirichlet or Neumann boundary conditions, and it does not substantially increase the number of iterations required for convergence over the case of a fixed basal velocity.

\section{Stress retreat}

\subsection{Assumptions}

The aim of this study is to quantify the effects of submarine frontal melting on calving rate. To this end, some assumptions must be made about the calving criterion. It is assumed that calving behaviour is determined solely by the viscous properties of ice, neglecting any effects due to elastic deformation. This greatly simplifies the calculation of stresses, and is in line with most glaciological practice.

It is also assumed that the variable of greatest interest is the (Cauchy) stress, rather than the strain rate (or equivalently, deviatoric stress). This is supported by Vaughan (1993), who notes that strain rates at crevasse sites vary by almost three orders of magnitude while stresses are almost constant. For simplicity, only the first (most tensile) principal stress is considered, as it is assumed to be the controlling factor on fracture. External sources of stress are ignored, based on the analysis of Bassis et al. (2008).

The question then arises as to where to evaluate the stress in order to determine where calving will occur. Here we follow the heuristic argument of Benn et al. (2007a), and thus our results are applicable to the calving criterion described therein. However, we note that our results hold qualitatively for more general calving criteria, as long as the general dependence on the first principal stress is maintained.

It is known (Weertman, 1973) that water-filled crevasses are likely to penetrate the full thickness of the glacier, under most realistic stress conditions. This occurs because, as water is denser than ice, hydrostatic pressure within the crevasse grows more quickly than the glaciostatic pressure around it. Thus a crack containing water should continue to grow until it reaches the base of the glacier. Therefore, if we assume that crevasses which reach below the waterline are likely to contain water, we can disregard the stresses which occur at depths much below the waterline, for the purposes of calculating crevasse depths.

Similarly, if we assume that the dominant control on the crevasse's growth is the stress field around the crack tip, the stress field near to the surface of the glacier is irrelevant, once the crack has grown beyond a certain size. In essence, the waterline acts as a sort of threshold: cracks which pass this point will eventually reach the base of the glacier, while cracks which do not will remain as irrelevant surface features. Thus the most important factor in determining whether the crevasse penetrates the whole glacier is the stress field around the waterline.

We note at this point that, while our results depend quantitatively on the choice of the waterline as this threshold, they should be qualitatively applicable if some other threshold is chosen. Although the numbers involved are likely to change, the broad conclusions should remain valid in a more general context. 
Finally, it is assumed that internal deformation of the glacier takes place on timescales much longer than those associated with calving or frontal melting. This follows from the calculation of van der Veen (2002), who showed that a typical tidewater glacier front deforms at a rate which is between one and two orders of magnitude too slow to be responsible for calving.

It therefore suffices to look only at the cumulative amount of frontal melt, rather than the rate at which it occurs. Another advantage of this assumption is that it can be internally verified by using the stress field to calculate instantaneous velocities. Note that no assumption is made about the absolute velocity of the glacier, merely about the rate at which it is deforming internally. In fact, for a stable calving front it is necessary that the glacier sliding velocity is of a similar order to the calving rate, and thus must take place on the same timescale.

\subsection{Definitions}

In this study, the dimensionless dry calving length $\varepsilon$ is defined as the aspect ratio of the incipient iceberg, when no frontal melt is occurring. Thus, for a glacier of thickness $H$, the distance from the ice front to the point of calving is $\varepsilon H$ (Fig. 1). While this measure is undoubtedly variable, and may even include a stochastic component, it is fixed for a given calving event. It is also useful to define the undercut length $d$ as the depth-averaged cumulative frontal melt, and the dimensionless waterline height $h$ as the ratio of the glacier depth below sea level to the full glacier thickness.

The central concept of this analysis is the "stress retreat", which is a measure of the spatial effect of a stress perturbation, defined as follows: A reference frame is used whereby $x$ is a horizontal variable, increasing inland from zero at the ice front. Given a reference stress state $\sigma_{\text {ref }}(x)$ and a perturbed state $\sigma_{\text {pert }}(x)$, the stress retreat $r$ is the minimum distance inland such that $\sigma_{\text {ref }}(x)=\sigma_{\text {pert }}(x+r)$. In other words, the effect of the perturbation is to move the stress field inland by a distance $r$. This distance is, of course, a function of position $x$, and may vary considerably. In all cases considered here, $r$ is positive and finite.

Intuitively, the stress retreat can be thought of as the distance that the stress field is "pushed back" by a perturbation, such as undercutting or a change in the frontal boundary condition. Ice in this situation will behave as though it were this distance further forward in an unperturbed glacier.

Finally, the wet calving multiplier $\omega$ is defined as $r / d$, where $r$ is the stress retreat due to an undercut length $d$. From first principles, there is no reason to suppose that $\omega$ is independent of $d$, but this shall be shown empirically to be the case in Sect. 4.

The ratio $\omega$ can be interpreted as follows: Assuming, in the absence of frontal melting, that the conditions for calving exist at a point $x$, then after a quantity of frontal melting $d$, those same conditions exist at the point $x+r=x+\omega d$. Thus,

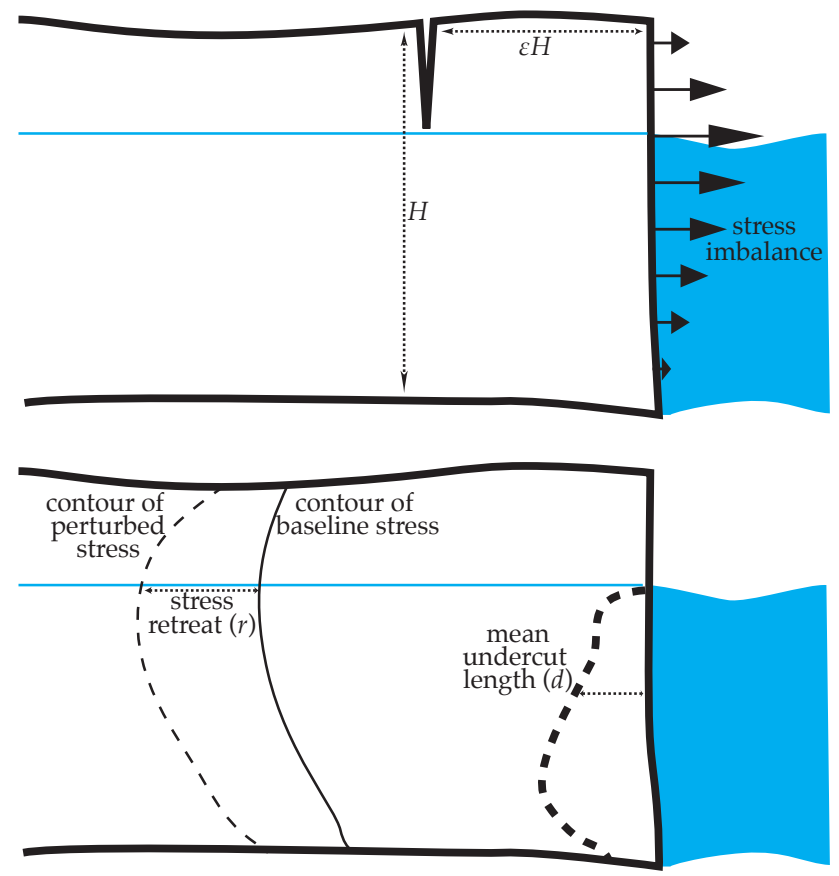

Fig. 1. Above: schematic of the geometry used in this study. Below: schematic of change in stress due to an undercut. The stress retreat $r$ is the distance between a stress contour in the baseline state, and the equivalent contour in the perturbed state, measured along the waterline.

if calving is occurring at an interval $\Delta t$, leading to a dry calving rate of $x / \Delta t$, the calving rate once frontal melting is incorporated will be equal to $x / \Delta t+\omega d / \Delta t$, an increase of $\omega$ times the mean melt rate.

It may therefore be useful to treat $\omega$ as a measure of the sensitivity of the calving rate to variations in frontal melt rate, with a value of one corresponding to a simple additive model. Such a way of thinking about the effects of submarine melt is the dominant one in those works which include melting in the frontal mass balance calculation (Motyka et al., 2003; Amundson and Truffer, 2010). While such an approach is observationally correct - there is no easy way to distinguish frontal melt-driven calving from any other kind - it will be found more productive here to make this distinction, and to separate "dry" melt-free calving from "wet" frontal melt-driven calving.

However, this interpretation must be used with care. An increase in the mean size of a calving event is likely to have repercussions on the dynamics of the glacier. As such, the effects described here should be considered merely one component of a system of interacting processes and feedbacks, which ultimately determine the behaviour of the glacier. 


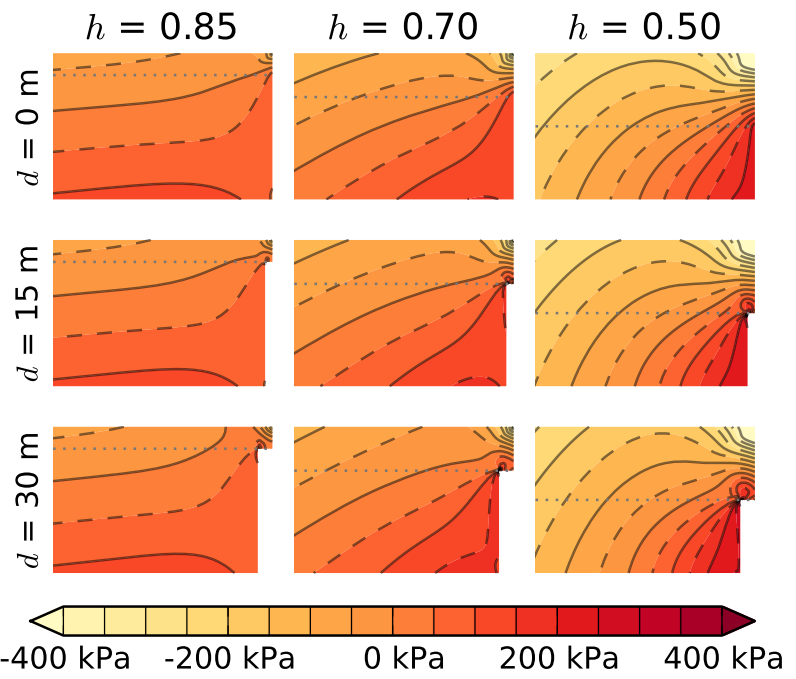

Fig. 2. Comparison of first principal Cauchy stresses, relative to hydrostatic pressure, for a variety of water depths and undercut lengths, assuming uniform undercutting. Grey dashed line indicates water level.

\section{Wet calving multiplier}

In order to calculate the effects of undercutting on nearfrontal stress, the flow model is used to compute stress fields in a variety of configurations. As a baseline unperturbed model run, meant to simulate a typical medium-sized tidewater glacier, the model is run in a flat rectangular slab configuration. The ice thickness is $300 \mathrm{~m}$, and the basal parameters are $\lambda^{*}=20 \mathrm{~m}$ and $m^{*}=0.13$ - see below for the sensitivities to these parameters. The water level varies between model runs, as the results are quite sensitive to this variable.

By altering the shape of the domain, the effect of undercutting by frontal melt can be simulated. Figure 2 shows the deviatoric stress fields generated by a selection of geometries and water levels, assuming uniform frontal melt below sea level, and an isothermal glacier. Qualitatively, it seems clear that undercutting results in an increase in tension due to the bending moment exerted by the overhang, as well as the reduction in basal traction near the glacier foot. These effects increase with the undercut length $d$ and show qualitative variation with the water level $h$.

Figure 3 shows the stress retreat as a function of undercut length for a variety of scenarios. In each case, a uniform undercut is introduced and the stress retreat measured, relative to a particular dry calving length $\varepsilon$. For each scenario, a linear fit through the origin is possible, with $R^{2}>0.99$. The slope of this fit is equal to the wet calving multiplier $\omega$, which is henceforth assumed to be independent of the undercut length. Although this assumption must certainly break down at large undercut lengths, it appears to hold for undercut lengths which are up to $20 \%$ of an ice thickness, far larger than the expected depth of real-world undercuts.

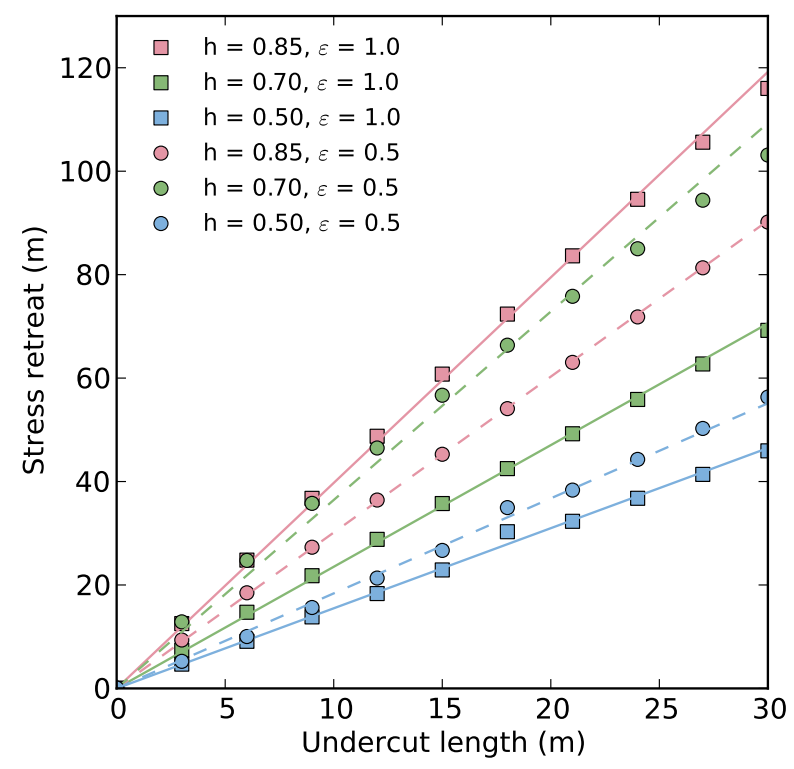

Fig. 3. Stress retreat as a function of undercut length for a variety of scenarios involving different water depths $h$ and dry calving lengths $\varepsilon$. In all cases the relationship is very close to linear. The slope of the linear fit is $\omega$, the wet calving multiplier.

\section{Sensitivities}

Given that $\omega$ is well-defined for a given scenario, the question remains as to what factors influence its value. The most obvious of these is the dry calving length $\varepsilon$. As this is used as the initial point from which the stress retreat is measured, it should come as no surprise that the magnitude of the stress retreat (and hence $\omega$ ) is dependent on its value.

For a grounded or partially grounded glacier, values of $\varepsilon$ greater than one are usually held to be unlikely, given that the resulting berg would be unable to capsize, and would thus have no obvious route of escape from the glacier. Here, the upper limit is drawn at a value of $\varepsilon=1.5$, to allow for some leeway in the system. Similarly, values of $\varepsilon<0.25$ are neglected, as such narrow calving events are likely to be much more affected by the detailed geometry of the front than by viscous stresses. However, it should be noted that they are not ruled out by this model, merely likely to be modelled incorrectly.

Another variable of interest is the water depth, or more loosely, the "degree of grounding". As there is known to be a significant difference in calving behaviour between grounded and floating glaciers (Walter et al., 2010), it seems reasonable to suggest that the water level may have a significant qualitative effect on calving, even if the transition is not as abrupt as that between grounded and floating ice. As such, a selection of water depths are investigated, ranging from $h=0.5$, for a well-grounded glacier, to $h=0.85$, a glacier almost at the point of flotation. Flotation occurs at $h=\rho_{\mathrm{i}} / \rho_{\mathrm{w}} \simeq 0.89$, at which point the calculations of the model diverge in a nonuseful manner. 


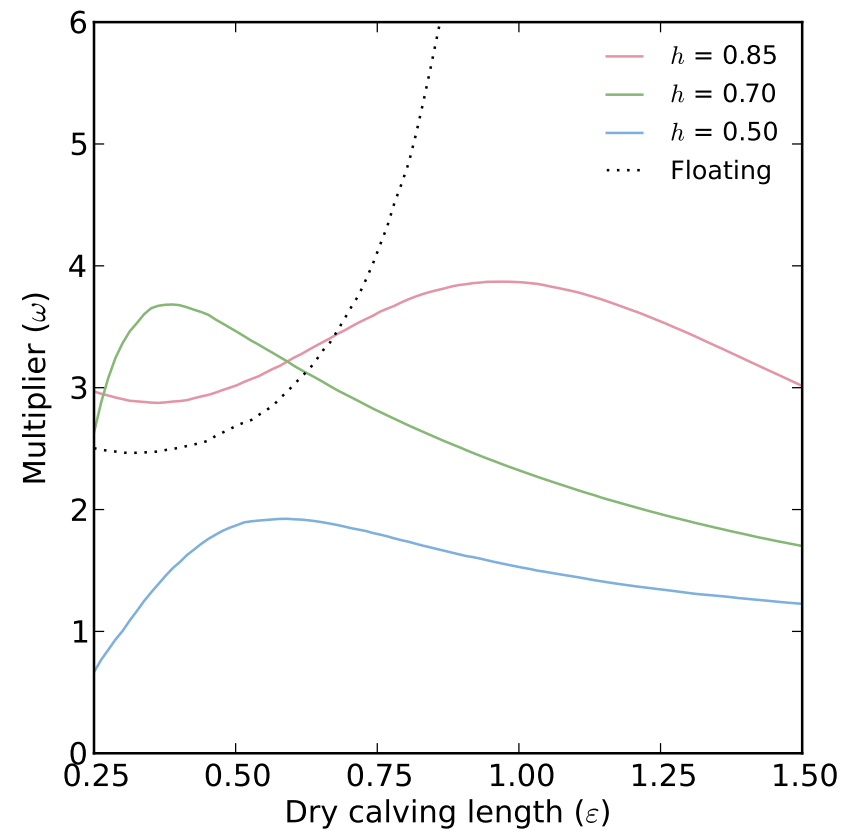

Fig. 4. Relationship of wet calving multiplier $\omega$ to calving length $\varepsilon$ for varying water depths. Also shown is the floating case, where $\omega$ rapidly diverges.

As can be seen in Fig. 4, typical values of $\omega$ for the simplest scenarios are in the range $1-4$, indicating that in this idealized situation, frontal melt drives calving at a rate up to four times the mean melt rate. Higher water levels generally lead to larger values of the multiplier $\omega$, as do shorter calving lengths. In the $h=0.5$ case, where the glacier is immersed in water to its midpoint, the multiplier effect is relatively weak, with frontal melt-driven calving occurring at around one and a half times the melt rate. The effect is much stronger in the more typical $h=0.7$ case, with a multiplier in the range of two to three.

The highest values of $\omega$ are usually found at $\varepsilon \simeq 1-h$, indicating that the geometry of the above-water portion of the nascent iceberg is important. At calving lengths shorter than this, there is some drop-off in the value of $\omega$, although as previously stated, the model may not be fully capturing the complexities of the stress field so close to the front.

Glaciers close to flotation also show an increase in $\omega$ for calving lengths of around an ice thickness, foreshadowing the divergence in $\omega$ when the glacier comes afloat. However care should be taken in interpreting this result, as the stress distribution becomes very uniform here, and in reality stress variations from other sources will probably play more of a role.

Significantly, in all but a few cases, $\omega$ is greater than one. This means that undercutting could be driving calving at rates greater than the frontal melt rate itself, providing an amplification of the oceanographic forcing on the glacier. This ef-

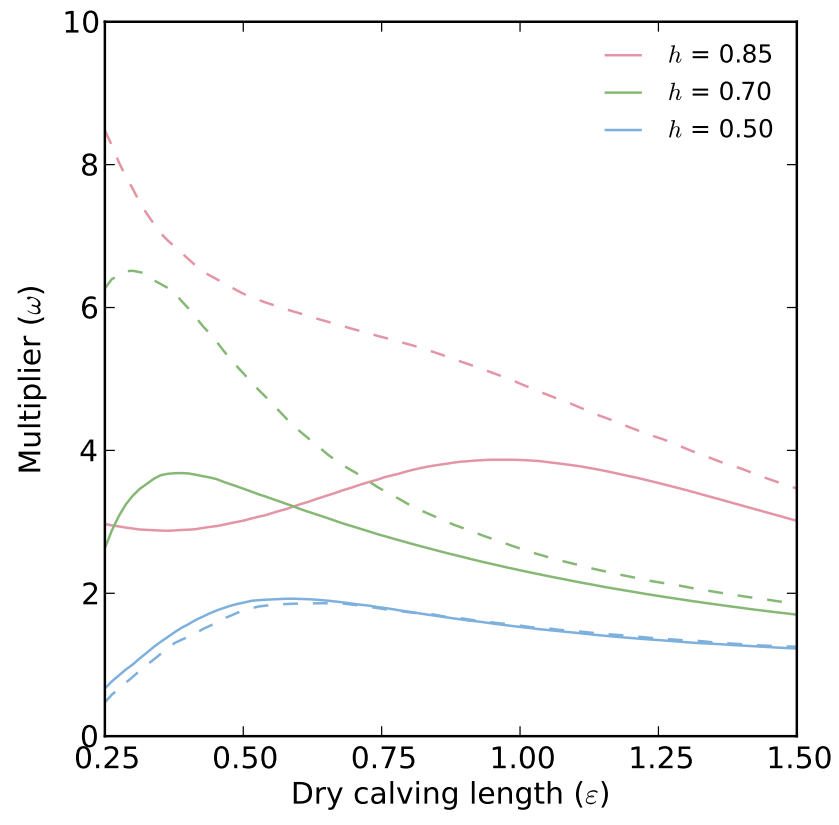

Fig. 5. The effect of a temperature gradient on the $\omega-\varepsilon$ relationship. Solid lines show the baseline cases, while dashed lines show the relationship when a $10^{\circ} \mathrm{C}$ temperature gradient is applied. For lightly grounded glaciers, there is a positive effect, while heavily grounded glaciers see almost no difference.

fect will be most strongly felt on those glaciers which are themselves well immersed in water. This may go some way towards explaining the empirical relationships which have been identified between calving and water depth (Sikonia, 1982; van der Veen, 1996).

\subsection{Thermal regime and viscosity}

Given that many ice sheets are far from isothermal (Paterson, 2000), it might be assumed that the thermal regime of their outlet glaciers is similarly heterogeneous. Although mechanisms have been suggested by which the hydrological system of a glacier could result in near-isothermal conditions (Phillips et al., 2010), this has not been widely observed in the field. As such, it is useful to consider the effects of a thermal gradient on the frontal melt-calving relationship.

For simplicity, a linear temperature trend within the ice is assumed, ranging from $-10^{\circ} \mathrm{C}$ at the surface to $0^{\circ} \mathrm{C}$ at the bed. The effect of pressure on the melting point is neglected for simplicity. The effects are shown in Fig. 5. In general, for glaciers close to flotation, the effect of the temperature gradient is to boost $\omega$, in some cases by around a factor of two. For more heavily grounded glaciers, such as the $h=0.5$ case, the effect is very slightly negative.

The implication here is that glaciers in colder regions, with less developed hydrological systems and thus less homogeneous temperature profiles, are likely to be more severely 
impacted by a constant degree of undercutting, although these glaciers are also likely to be in colder marine environments, which will tend to decrease the quantity of submarine melt. In fact, higher atmospheric temperatures and the consequent surface melt may act to stabilize glacier fronts, by reducing the effects of undercutting on calving, if surface meltwater is sufficient to render the glacier temperate near the front.

It is likely that a two-part classification scheme is necessary here, distinguishing both between polar and temperate glaciers as is usual, but also between those terminating in warm and cold water. While there is certainly a strong correlation between the two groups, the relationship is imperfect, and there are certainly examples in Greenland of "cold" glaciers coming in contact with relatively warm water (Rignot et al., 2010; Sutherland and Straneo, 2012; Christoffersen et al., 2012). It has also been shown (Seale et al., 2011) that the behaviour of tidewater glaciers in Greenland respects strong geographical boundaries, which are more associated with oceanic than atmospheric or glacial temperatures.

Up until now, the glacier has been treated as a completely solid block of ice. In reality, the upper surface of a tidewater glacier is often heavily crevassed, resulting in reduced strength in the upper layers. Crevassing such as this is often represented in flow models through the use of an enhancement factor, which reduces the effective viscosity of the ice in such areas. Now, an enhancement factor is applied, reducing the effective viscosity above the waterline. At the surface the viscosity is reduced by a factor of ten, and this reduction is scaled linearly with depth until the viscosity reaches its normal value, $5 \mathrm{~m}$ above the waterline. This height is chosen so as to minimise the effects of a "kink" in the effective viscosity at the waterline, which interferes with the accurate calculation of stresses.

The effects of this change can be seen in Fig. 6. While there are some small differences, it is quite likely that these are due to numerical inaccuracies, due in large part to the "kink" in the effective viscosity near the waterline. In general, it seems that the rheology of the above-water portion of the glacier has very little effect on the value of $\omega$. This is a very helpful result, as it provides some validation for the approach of using an idealized slab glacier model.

\subsection{Basal boundary condition}

The basal boundary condition is one of the most uncertain elements in any glacier model. Therefore, it seems prudent to check that the results given here are robust against changes in this area. As a simple test, the boundary condition given in Eq. (8) is replaced with a simple linear relationship between sliding velocity and basal traction, with the constant of proportionality $\left(50 \mathrm{~Pa} \mathrm{a} \mathrm{m}^{-1}\right)$ chosen to best match the velocities of the more complex model.

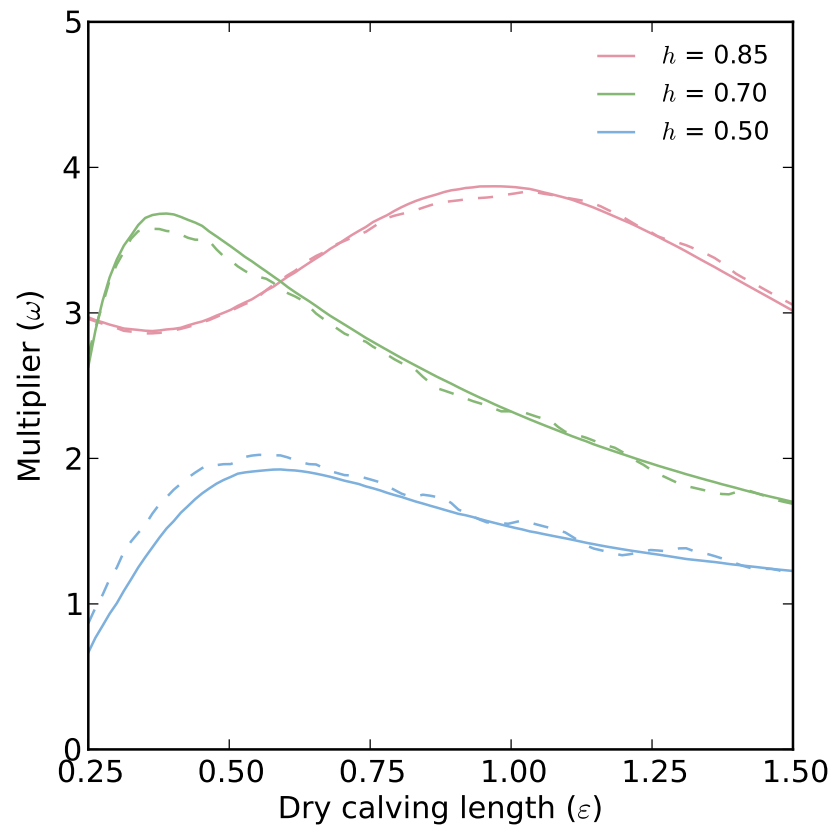

Fig. 6. The effect of surface damage on the $\omega-\varepsilon$ relationship. Dashed lines show the relationship when an enhancement factor is applied to the upper layers. No discernible pattern is visible, and the difference is likely to be a numerical artifact.

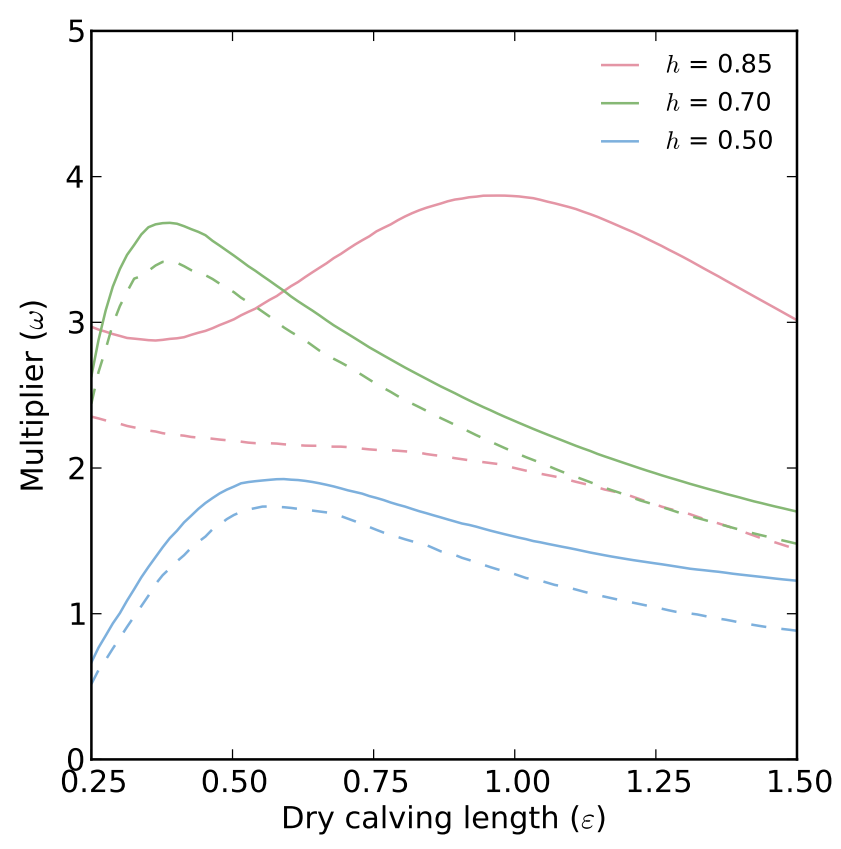

Fig. 7. The effect of a change in basal boundary condition on the $\omega-\varepsilon$ relationship. Dashed lines show the relationship with an extremely simple linear basal boundary condition. The most significant change is the reduction in $\omega$ for the $h=0.85$ case. 
The results are shown in Fig. 7. The largest effect is the reduction in the value of $\omega$ for the nearly floating case, as the changes in effective pressure at the bed no longer can have any effect. In the other cases, there is a small decrease in the value of $\omega$, but the general pattern remains very similar. Therefore it can be concluded that the basal boundary condition has little effect on this particular calving mechanism.

Another possible source of variability is the glacier thickness itself. Although it can be argued through dimensional analysis that most of the physics should be unchanged by an increase or decrease in physical scale, there are some effects surrounding the basal boundary condition which do not scale in a simple way. However, sensitivity tests (not shown) indicate that the glacier thickness is unimportant, with the resulting graphs being visually indistinguishable. As such, the results given here can be thought of as independent of glacier thickness.

\subsection{Undercut shape}

Another consideration, which has to this point been ignored, is the vertical distribution of melt over the glacier face. As estimates of frontal melt rates have generally arisen from heat balance calculations, there is no empirical evidence to suggest a particular form for the frontal melt profile. However, given the modelling results of Jenkins (2011), it should be expected that the frontal melt rate would be vertically inhomogeneous.

An attempt can be made to quantify the effect of this inhomogeneity by using a variety of different idealized frontal melt profiles. As well as the uniform profile used thus far, the model can be run using undercuts in wedge shapes, as well as a parabolic curve which peaks in the center of the submarine ice face. Note that in all cases, the undercut length used in calculations is the mean melt rate on the ice face. This is equivalent to half the maximum frontal melt rate for the wedge shapes, or two thirds that in the parabolic case.

Figure 8 shows the results of these tests. The differences are large. The basal wedge results in values of $\omega$ which are consistently about $50 \%$ greater than those in the uniform case. The surface wedge, by contrast, results in values which barely get above one, meaning that in this case, the simple additive approach is sufficient. Interestingly, the parabolic profile has a similar value of $\omega$ to the uniform case for small values of $\varepsilon$, but it drops off much more quickly for larger values.

Looking at the stress distributions, it can be suggested that the reason for the large value of $\omega$ in the basal wedge case is the movement of the "fulcrum" about which the glacier is bending to the base of the glacier. This area is visible in Fig. 8 as a region of high deviatoric stress. While the surface wedge case includes much higher stresses, they occur at the waterline and thus have only local effects.
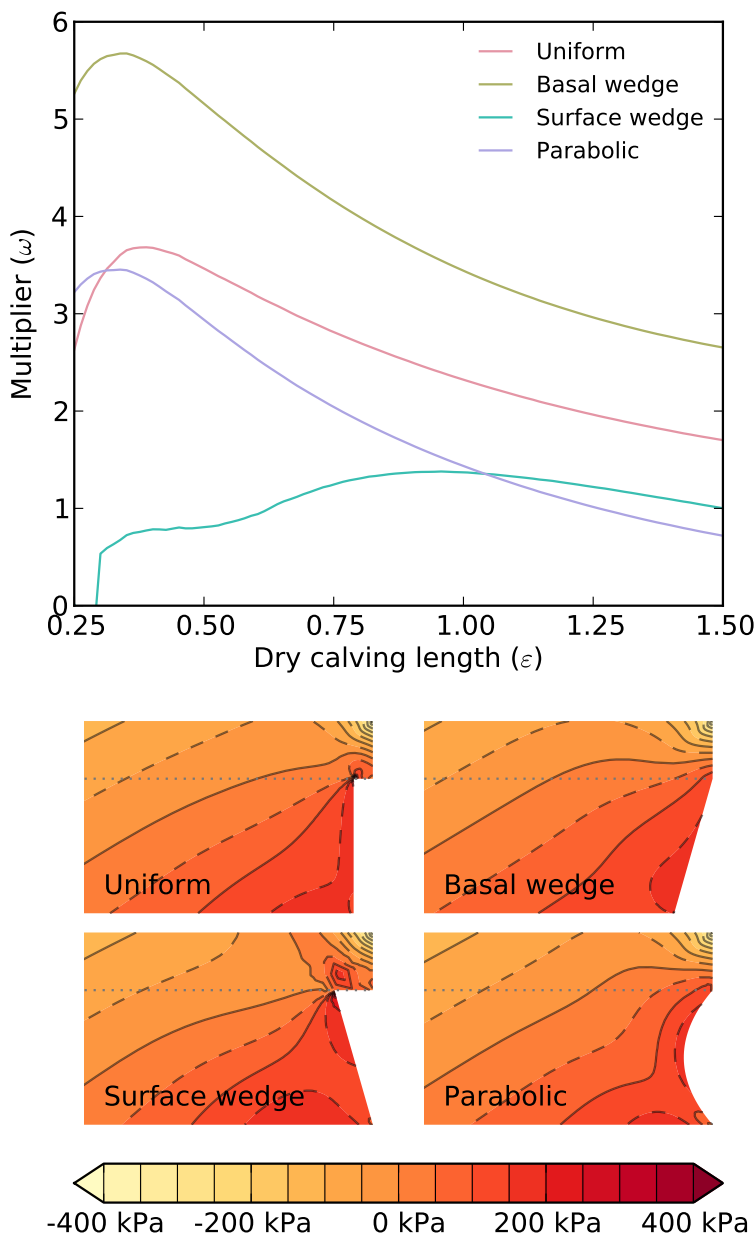

Fig. 8. Above: the $\omega-\varepsilon$ relationship for a variety of frontal melt profiles $(h=0.7)$. Below: Cauchy stress fields (relative to hydrostatic pressure) associated with frontal melt profiles.

\subsection{Surface slope}

A related issue to that of the undercut geometry is the geometry of the above-water portion of the ice, or, equivalently, the surface slope of the glacier. For simplicity of modelling, and due to the extremely complex and variable nature of real glacier geometries, we restrict our attention here to constant surface slopes.

Figure 9 shows the effect of a $5^{\circ}$ surface slope on the calving multiplier. As might be expected, this has the effect of reducing the multiplier, relative to a glacier with a flat surface, as the sloped glacier is effectively "more grounded" inward of the front, a situation which we have shown results in a reduced multiplier. However, the effect is still significant, particularly at short calving lengths.

In the event of a reverse surface slope, as observed at Helheim and Kangerdlugssuaq by Joughin et al. (2008), we should expect a similarly reversed effect on the multiplier. 


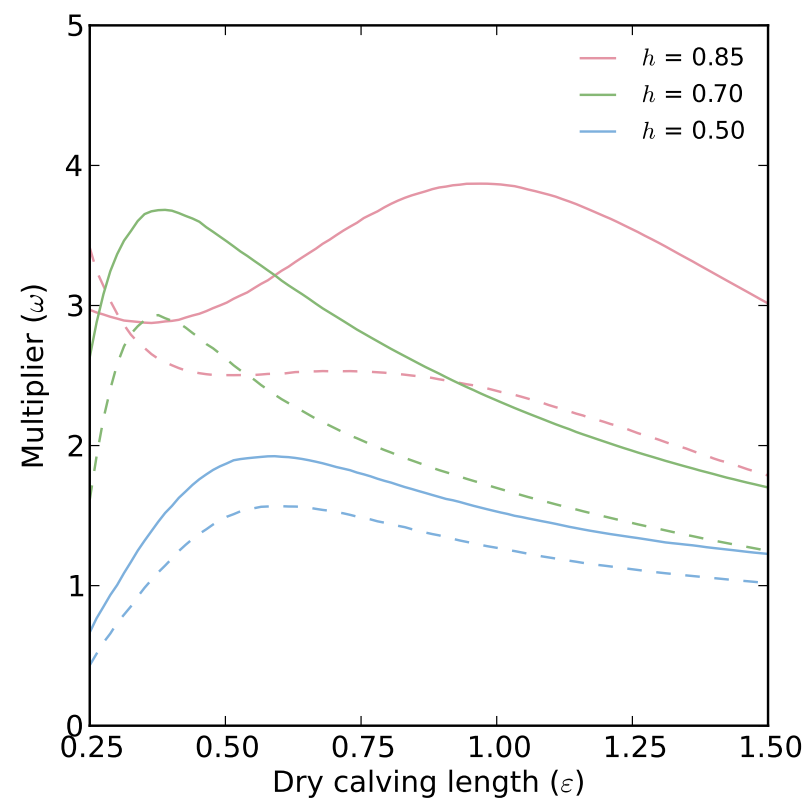

Fig. 9. The effect of a change in surface slope on the $\omega-\varepsilon$ relationship. Dashed lines show the relationship with a surface slope of $5^{\circ}$. Note that in this case, $h$ refers to the waterline height at the ice front only, with effectively smaller values of $h$ further from the front.

This is likely to lead to enhanced calving at longer lengths, as was observed by that study.

Owing to numerical simplifications in our model, we are unable to investigate the effects of a bed slope. While we believe these effects are likely to be quantitatively significant, we expect that they will not change the main qualitative conclusions of this study. Future work, applying this approach to real-world glacier conditions, will likely need to incorporate such effects.

\section{Conclusions}

By comparing modelled static stress fields in an idealized tidewater glacier, both with and without undercutting at the front, we have shown that submarine frontal melting is likely to lead to larger calving events, and thus an increase in the overall calving rate. This effect is linear in the length of the undercut, and therefore the rate of additional calving can be calculated as a simple multiple of the submarine melt rate, which we term the calving multiplier.

In the simplest case of an isothermal block glacier with uniform melt, the calving multiplier is between one and four, increasing as the glacier approaches flotation. The effect is enhanced considerably in the case where a thermal gradient is present within the glacier. This demonstrates the importance of accurate information about ice temperatures to the modelling of calving processes.

The effect of undercutting on calving is broadly insensitive to changes in basal friction, ice thickness, and the viscosity of the upper part of the glacier. This last variable can be understood as a proxy for the level of crevassing which is present in the glacier, and this result provides some reassurance that the results of our simplified block model should be applicable to more realistic glaciers.

The vertical distribution of melt on the glacier front has a strong influence on the calving multiplier, with the largest values occurring when melt is concentrated near the base of the glacier. This underscores the importance of deep water temperatures to the glacier's behaviour. It also indicates that vertically averaged estimates of melt rates, as currently available, may be insufficient to predict the follow-on effects of submarine frontal melting.

Finally, the presence of a steep surface slope results in a small decrease in the calving multiplier, as compared to a flat glacier with the same thickness at the ice front. This is consistent with the previously described result that the calving multiplier is higher when the glacier is near flotation.

When combined, these results indicate that those glaciers which are most vulnerable to increased calving due to changes in ocean temperature are glaciers which are near flotation, and which have a strong thermal gradient. They also indicate that water temperatures near the base of the glacier front are likely to have the greatest effect on calving. As a result, it is likely that sea surface temperatures are a poor indicator of how much influence the ocean is having on calving.

Our interpretation of these results should be used with some caution, however, as the model used is a drastic simplification of the true physics. A more detailed and accurate understanding of these phenomena will require a fully-coupled time-evolving model incorporating both ice flow and frontal melting, as well as the specification of a particular calving criterion.

Acknowledgements. This work was supported through a NERC Doctoral Training Grant to M. O'Leary. M. O'Leary was partially supported through NASA grant NNX08AN59G and NSF grant ARC1064535. We are grateful to N. Arnold, D. Benn, J. Bassis and an anonymous reviewer for their comments on this work, which have been very helpful in the development of the manuscript. We also acknowledge the assistance of the editor, O. Gagliardini, whose comments greatly improved this work.

Edited by: O. Gagliardini

\section{References}

Amundson, J. M. and Truffer, M.: A unifying framework for iceberg-calving models, J. Glaciol., 56, 822-830, doi:10.3189/002214310794457173, 2010.

Bassis, J. N., Fricker, H. A., Coleman, R., and Minster, J.-B.: An investigation into the forces that drive ice-shelf rift propagation on the Amery Ice Shelf, East Antarctica, J. Glaciol., 54, 17-27, doi:10.3189/002214308784409116, 2008.

Benn, D. I., Wiseman, S., and Hands, K. A.: Growth and drainage of supraglacial lakes on debrismantled Ngozumpa Glacier, Khumbu Himal, Nepal, J. Glaciol., 47, 626-638, doi:10.3189/172756501781831729, 2001. 
Benn, D. I., Hulton, N. R. J., and Mottram, R. H.: "Calving laws", "sliding laws" and the stability of tidewater glaciers, Ann. Glaciol., 46, 123-130, doi:10.3189/172756407782871161, 2007a.

Benn, D. I., Warren, C. R., and Mottram, R. H.: Calving processes and the dynamics of calving glaciers, Earth-Sci. Rev., 82, 143179, doi:10.1016/j.earscirev.2007.02.002, 2007b.

Christoffersen, P., O'Leary, M., van Angelen, J. H., and van den Broeke, M.: Partitioning effects from ocean and atmosphere on the calving stability of Kangerdlugssuaq Glacier, East Greenland, Ann. Glaciol., 53, 249-256(8), 2012.

Cook, S., Zwinger, T., Rutt, I. C., O’Neel, S., and Murray, T.: Testing the effect of water in crevasses on a physically based calving model, Ann. Glaciol., 53, 90-96, doi:10.3189/2012AoG60A107, 2012.

Gagliardini, O., Cohen, D., Råback, P., and Zwinger, T.: Finiteelement modeling of subglacial cavities and related friction law, J. Geophys. Res., 112, F02027, doi:10.1029/2006JF000576, 2007.

Glen, J.: Experiments on the deformation of ice, J. Glaciol., 2, 111114, 1952.

Hanson, B. and Hooke, R. L.: Glacier calving: a numerical model of forces in the calving-speed/water-depth relation , J. Glaciol., 46, 188-196, doi:10.3189/172756500781832792, 2000.

Hecht, F., Pironneau, O., Le Hyaric, A., and Ohtsuka, K.: Freefem++, UPMC-LJLL Press, 2005.

Howat, I. M., Joughin, I., and Scambos, T. A.: Rapid Changes in Ice Discharge from Greenland Outlet Glaciers, Science, 315, 15591561, doi:10.1126/science.1138478, 2007.

Iken, A.: The effect of subglacial water pressure on the sliding velocity of a glacier in an idealized numerical model, J. Glaciol., 27, 407-422, 1981.

Jenkins, A.: Convection-driven melting near the grounding lines of ice shelves and tidewater glaciers, J. Phys. Oceanogr., 41, 22792294, 2011.

Joughin, I., Abdalati, W., and Fahnestock, M.: Large fluctuations in speed on Greenland's Jakobshavn Isbræ glacier, Nature, 432, 608-610, doi:10.1038/nature03130, 2004.

Joughin, I., Howat, I., Alley, R. B., Ekstrom, G., Fahnestock, M., Moon, T., Nettles, M., Truffer, M., and Tsai, V. C.: Icefront variation and tidewater behavior on Helheim and Kangerdlugssuaq Glaciers, Greenland, J. Geophys. Res., 113, F01004, doi:10.1029/2007JF000837, 2008.

Kirkbride, M. P. and Warren, C. R.: Calving processes at a grounded ice cliff, Ann. Glaciol., 24, 116-121, 1997.

Luckman, A., Murray, T., de Lange, R., and Hanna, E.: Rapid and synchronous ice-dynamic changes in East Greenland, Geophys. Res. Lett., 33, L03503, doi:10.1029/2005GL025428, 2006.

Mottram, R. H. and Benn, D. I.: Testing crevasse-depth models: a field study at Breidamerkurjökull, Iceland, J. Glaciol., 55, 746752, doi:10.3189/002214309789470905, 2009.

Motyka, R. J., Hunter, L., Echelmeyer, K. A., and Connor, C.: Submarine melting at the terminus of a temperate tidewater glacier, LeConte Glacier, Alaska, U.S.A., Ann. Glaciol., 36, 5765, doi:10.3189/172756403781816374, 2003.

Nick, F. M., van der Veen, C. J., Vieli, A., and Benn, D. I.: A physically based calving model applied to marine outlet glaciers and implications for the glacier dynamics, J. Glaciol., 56, 781-794, doi:10.3189/002214310794457344, 2010.
Paterson, W. S. B.: The Physics of Glaciers, ButterworthHeinemann, 3rd Edn., 2000.

Phillips, T., Rajaram, H., and Steffen, K.: Cryo-hydrologic warming: A potential mechanism for rapid thermal response of ice sheets, Geophys. Res. Lett., 37, L20503, doi:10.1029/2010GL044397, 2010.

Pimentel, S., Flowers, G. E., and Schoof, C. G.: A hydrologically coupled higher-order flow-band model of ice dynamics with a Coulomb friction sliding law, J. Geophys. Res., 115, F04023, doi:10.1029/2009JF001621, 2010.

Reeh, N.: On the calving of ice from floating glaciers and ice shelves, J. Glaciol., 7, 215-232, 1968.

Rignot, E. and Kanagaratnam, P.: Changes in the Velocity Structure of the Greenland Ice Sheet, Science, 311, 986-990, doi:10.1126/science.1121381, 2006.

Rignot, E., Koppes, M., and Velicogna, I.: Rapid submarine melting of the calving faces of West Greenland glaciers, Nat. Geosci., 3, 187-191, doi:10.1038/ngeo765, 2010.

Röhl, K.: Thermo-erosional notch development at fresh-watercalving Tasman Glacier, New Zealand, J. Glaciol., 52, 203-213, doi:10.3189/172756506781828773, 2006.

Schoof, C.: The effect of cavitation on glacier sliding, P. Roy. Soc. A-Math. Phys., 461, 609-627, doi:10.1098/rspa.2004.1350, 2005.

Seale, A., Christoffersen, P., Mugford, R. I., and O'Leary, M.: Ocean forcing of the Greenland Ice Sheet: Calving fronts and patterns of retreat identified by automatic satellite monitoring of eastern outlet glaciers, J. Geophys. Res., 116, F03013, doi:10.1029/2010JF001847, 2011.

Sikonia, W. G.: Finite element glacier dynamics model applied to Columbia Glacier, Alaska, Tech. Rep. 1258-B, USGS, 1982.

Stearns, L. A. and Hamilton, G. S.: Rapid volume loss from two East Greenland outlet glaciers quantified using repeat stereo satellite imagery, Geophys. Res. Lett., 34, L05503, doi:10.1029/2006GL028982, 2007.

Sutherland, D. and Straneo, F.: Estimating ocean heat transports and submarine melt rates in Sermilik Fjord, Greenland, using lowered acoustic Doppler current profiler (LADCP) velocity profiles, Ann. Glaciol., 53, 50-58, 2012.

van der Veen, C. J.: Tidewater calving, J. Glaciol., 42, 375-385, 1996.

van der Veen, C. J.: Calving glaciers, Prog. Phys. Geog., 26, 96122, doi:10.1191/0309133302pp327ra, 2002.

Vaughan, D. G.: Relating the occurrence of crevasses to surface strain rates, J. Glaciol., 39, 255-266, 1993.

Vieli, A., Jania, J., and Kolondra, L.: The retreat of a tidewater glacier: observations and model calculations on Hansbreen, Spitsbergen, J. Glaciol., 48, 592-600, doi:10.3189/172756502781831089, 2002.

Walter, F., O’Neel, S., McNamara, D., Pfeffer, W. T., Bassis, J. N., and Fricker, H. A.: Iceberg calving during transition from grounded to floating ice: Columbia Glacier, Alaska, Geophys. Res. Lett., 37, L15501, doi:10.1029/2010GL043201, 2010.

Weertman, J.: Deformation of floating ice shelves, J. Glaciol., 3, 38-42, 1957a.

Weertman, J.: On the sliding of glaciers, J. Glaciol., 3, 33-38, $1957 b$.

Weertman, J.: Can a water-filled crevasse reach the bottom surface of a glacier?, IAHS Publication, 1973. 